\title{
A Note on Orthography
}

Maya words used in this text follow the modern orthography used in the Diccionario básico español-maya, maya-español by Ramón Bastarrachea, et al. (Mérida: Maldonado Editores, 1992). The only exceptions have been certain place names and last names that have retained certain traditional colonial spellings: for example, $h$ instead of $j, u$ for $w$, th instead of $t^{\prime}$, and $d z$ instead of $t s$.

English translations for the titles of folktales published in Spanish are my own.

All monetary values are in Mexican pesos and reales (one peso $=$ eight reales). 
THIS PAGE INTENTIONALLY LEFT BLANK 
Sour godliness is the Devil's religion.

- John Wesley on Calvinism

The day will come when you see

everything you do

reflected in a pool of water.

- Maya riddle 
THIS PAGE INTENTIONALLY LEFT BLANK 